\title{
Pengaruh Kualitas Layanan Elektronik (E-Servqual) terhadap Kepuasan Nasabah Pengguna Mobile Banking (Studi Pada Pengguna Mobile Banking Bank Sinarmas Cabang Malang)
}

\author{
Olivia Mimin Trisnawati \\ Program Studi Manajemen \\ Sekolah Tinggi Ilmu Ekonomi Kertanegara Malang \\ oliviami2110@gmail.com \\ Syaifuddin Fahmi \\ Program Studi Manajemen \\ Sekolah Tinggi Ilmu Ekonomi Kertanegara Malang \\ syaifuddin_fahmi@stiekma.ac.id
}

\begin{abstract}
Abstrak
Tujuan penelitian ini adalah untuk menganalisis pengaruh kualitas layanan mobile banking yang terdiri dari dimensi skala inti e-SERVQUAL (reability, efficiency, privacy, dan fulfillment) terhadap kepuasan nasabah. Jumlah sampeladalah 100 responden. Teknik analisis yang akan digunakan dalam penelitian ini adalah regresi linier berganda, yaitu untuk mengetahui besarnya pengaruh antara variabel bebas dengan variabel terikat.Hasil Uji $\mathrm{T}$ menunjukkan bahwa semua variabel berpengaruh signifikan terhadap kepuasan nasabah. Dari hasil analisis hipotesis diketahui bahwa 55,7\% kepuasan nasabah dapat dijelaskan oleh variabel reability, efficiency, privacy, dan fulfillment, sedangkan $44,3 \%$ dipengaruhi oleh variabel lain yang tidak ada dalam penelitian ini. Berdasarkan keseluruhan variabel, reability memiliki pengaruh terbesar terhadap kepuasan nasabah pengguna SimobiPlus.
\end{abstract}

Kata kunci: Kualitas Layanan Elektronik, Kepuasan Nasabah, Bank, Mobile Banking

\section{Pendahuluan}

Perkembangan teknologi informasi dan komunikasi membuat industri perbankan bersaing ketat dalam inovasi produk dan layanan elektronik perbankan. Kemampuan manajemen dalam mengadopsi teknologi baru sangat menentukan tingkat keberhasilan dalam pengembangan inovasi layanan (Gan, 2006). Mobile banking merupakan salah satu inovasi yang dikembangkan untuk melakukan transaksi keuangan perbankan melalui smartphone mulai dari cek saldo, transfer dana, informasi dan layanan perbankan lainnya yang dapat diakses kapanpun dan dimanapun (Ensor, 2012). Industri perbankan mulai memaksimalkan pemanfaatan smartphone terhadap layanan mobile banking sebagai layanan yang menggunakan teknologi tinggi (Suoranta, 2004). 


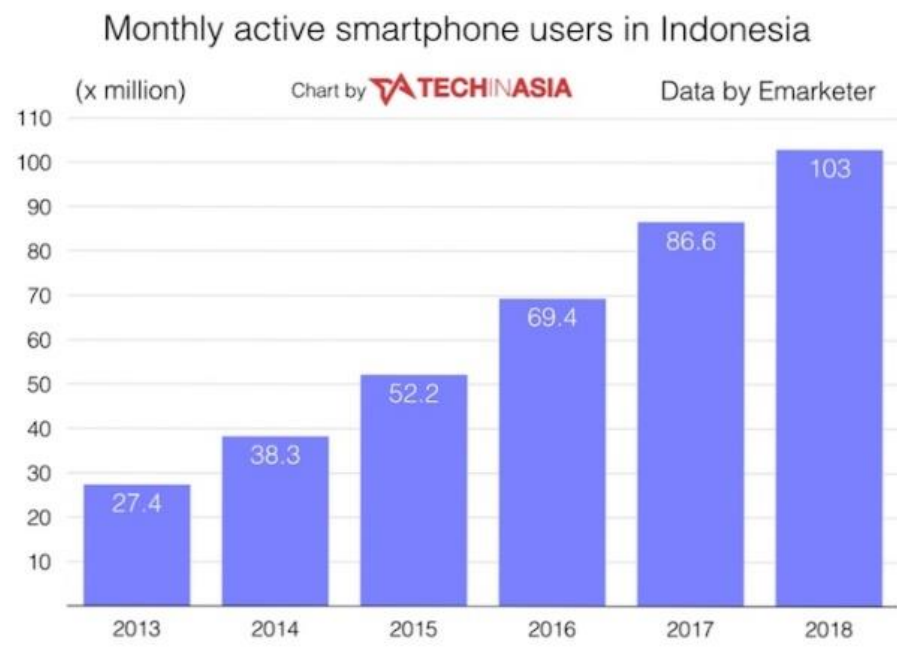

Gambar 1. Jumlah Pengguna Smartphone

Sumber : https://www.emarketer.com

Berdasarkan gambar 1, diperkirakan pada tahun 2018 lebih dari 2,56 miliar orang akan menggunakan smartphone. Angka itu juga mewakili lebih dari separuh 51,7\% dari semua pengguna ponsel. Menurut eMarketer selama periode perkiraan tahun 2018 Indonesia akan melewati 100 juta pengguna smartphone, yang ditetapkan sebagai populasi pengguna smartphone terbesar keempat. Dalam perkembangan mobile banking yang dapat dibilang paling cepat daripada digital banking lainnya, maka dibutuhkan layanan yang maksimal untuk mewujudkan kepuasan nasabah. Oleh sebab itu, industri perbankan di Indonesia mulai memaksimalkan pemanfaatan smartphone terhadap layanan mobile banking sebagai layanan yang menggunakan teknologi tinggi (Suoranta, 2004). Pelayanan yang sempurna (service exellent) dalam layanan perbankan elektronik adalah peran penting untuk meningkatkan kepuasan pelanggan.Metode SERVQUAL yang diusulkan oleh Parasuraman, et al. (1988) adalah salah satu teknik evaluasi terbaik untuk menilai harapan dan persepsi pelanggan.Zeithaml (2001)mengembangkan ukuran e-SERVQUAL untuk mempelajari bagaimana konsumen menilai kualitas layanan elektronik. Tujuh dimensi e-SERVQUAL adalah efficiency, fulfillment, reability, privacy, responsiveness, compensation, dan contact.

Bank Sinarmas merupakan salah satu bank konvensional swasta nasional yang berstatus sebagai bank devisa. Bank Sinarmas berdiri pada tanggal 18 Agustus 1989 dan memiliki lebih dari 385 kantor cabang yang tersebar di lebih dari 150 kota di Indonesia. Pada tahun 2007 Bank Sinarmas meningkatkan layanan elektonik perbankan atau lebih dikenal dengan e-banking (internet banking dan phone banking) sebagai fasilitas teknologi perbankan. Sinarmas Mobile Banking atau Simobi adalah layanan elektronik Bank Sinarmas yang dikembangkan untuk nasabah dalam mengelola transaksi keuangan dengan mudah melalui smartphone berbasis Iphone, Android, dan Blackberry. Tahun 2017, Bank Sinarmas telah mengembangkan aplikasi Simobi menjadi SimobiPlus untuk memudahkan layanan transaksi dengan EasyPin. EasyPin memudahkkan nasabah untuk mengakses mobile banking dan untuk otentikasi transaksi pada aplikasi SimobiPlus yang berupa 6 digit angka tanpa harus menggunakan token. SimobiPlus hadir dengan fitur yang lengkap dan menarik. Selain untuk transaksi keuangan, SimobiPlus juga melayani pembukaan rekening online, deposito online, dan layanan lainnya. Dengan inovasi layanan yang terus dikembangkan, Bank Sinarmas menerima berbagai penghargaan dalam berbagai kategori. Salah satunya adalah kategori best top IT Implementation on Mobile Internet Banking Development (Top IT 2017). Selain itu Bank Sinarmas juga merupakan salah satu peraih penghargaan kategori The Most Efficient Bank, kategori bank konvensional swasta nasional. 
Berdasarkan uraian di atas, rumusan penelitian ini adalah menganalis apakah kualitas layanan elektronik yang terdiri dari variabel efficiency, fulfillment, reability, dan privacy mempunyai pengaruh signifikan terhadap kepuasan pelanggan. Selain itu, makakah diantara keempat variabel yang mempunyai pengaruh terbesar dalam kepuasan pelanggan.Dengan demikian, tujuan penelitian ini adalah untuk mengetahui seberapa besar pengaruh variabel layanan Sinarmas mobile banking terhadap kepuasan nasabah Bank Sinarmas Cabang Malang.

\section{Landasan Teori dan Pengembangan Hipotesis}

Kepuasan adalah perasaan seseorang dalam membandingkan harapan dengan hasil yang dirasakan.Kualitas layanan adalah tingkat perbedaan antara harapan pelanggan terhadap layanan dan persepsi terhadap kinerja (Parasuraman, 1985).Mengetahui harapan pelanggan adalah langkah penting dalam menentukan dan memberikan layanan berkualitas tinggi (Zeithaml V. B., 1996). Harapan pelanggan memainkan peran penting untuk menentukan evaluasi dan kepuasan kualitas layanan (O'Connor, 2000). Oleh karena itu, banyak pelaku bisnis mempertimbangkan kualitas layanan untuk mendapatkan kepuasan dan loyalitas pelanggan (Gazor, 2012). Menurut Kasmir (2008), pengukuran tingkat kepuasan pelanggan ada empat cara, yaitu sistem keluhan dan usulan, survei kepuasan konsumen, konsumen samaran (mystery guest), dan analisis mantan pelanggan.

Dalam pengukuran tingkat kepuasan pelanggan, pelaku usaha harus mengukur langsung dengan berbagai pertanyaan mengenai pelayanan produk dan jasa yang diberikan, atau memberikan sarana agar pelanggan bisa menuliskan kritik atau saran serta merangking seberapa besar tingkat kepuasan yang pelanggan rasakan.Faktor yang memenuhi pelayanan sempurna, diantaranya pelayanan yang konsisten, menunjukkan rasa hormat kepada nasabah, menciptakan pengalaman yang berkesan kepada nasabah, tidak membeda-bedakan nasabah, selalu melayani sampai tuntas, menunjukkan rasa peduli kepada nasabah. Mobile banking dapat memberi dampak positif terhadap hubungan nasabah dengan bank. Service quality (SERVQUAL) adalah teknik modern untuk mengukur kualitas di berbagai perusahaan dan organisasi dan melayani pengembangan manajemen dan budaya yang berfokus pada pelanggan (Gazor, 2012).

Pengertian model e-SERVQUAL yang mencakup tujuh dimensi (efficiency, fulfillment, reability, privacy, responsiveness, compensation, dan contact) dijelaskan sebagai berikut :

1. Skala layanan inti pada e-SERVQUAL.

a) Efficiency: kemampuan pelanggan mencari informasi yang berkaitan dengan produk serta kemudahan dalam mengakses dan meninggalkan website dengan upaya minimal.

b) fulfillment: pemenuhan produk dan memberikan layanan yang diminta pelanggan secara benar dan tepat waktu.

c) Reability: kemampuan untuk melakukan layanan yang dijanjikan secara akurat dan dapat diandalkan.

d) Privacy: jaminan bahwa data dan transaksi pelanggan aman dan tidak dibocorkan.

2. Skala layanan pemulihan pada e-SERVQUAL.

a) Responsiveness: kemampuan memberikan informasi yang tepat kepada pelanggan ketika timbul masalah dan memiliki mekanisme pemberian garansi.

b) Compensation: pemberian ganti rugi kepada pelanggan ketika timbul kesalahan atau 
kegagalan sistem.

c) Contact: memberikan kemudahan komunikasi antara nasabah dengan staf secara online atau melalui telepon ketika pelanggan membutuhkan informasi terkait dengan produk dan layanan.

Skala layanan inti pada dimensi e-SERVQUAL adalah berkaitan dengan operasional pada saat pelanggan mengakses website, sedangkan untuk skala layanan pemulihan pada dimensi e-SERVQUAL berkaitan dengan penanganan apabila terjadi kegagalan (error)pada saat mengakses website.

Berdasarkan penelitian Fitri Kemala Effendi Jawas dan Abdullah (2015) dimensi layanan e-SERVQUAL yang terdiri dari efficiency, system availability, fulfillment, privacy, responsiveness, dan contact pada kualitas layanan BNI internet banking mendapat tanggapan baik dari nasabah. Total rata-rata persentase tanggapan yaitu variabel efficiency sebesar $76,20 \%$, system availability sebesar $73,81 \%$, fulfillment sebesar $74,48 \%$, privacy sebesar $76,94 \%$, responsiveness sebesar 70,94\%, dan contact sebesar 76,03\%. Kepuasan nasabah memiliki indikator yaitu ekspektasi dan performa layanan yang dirasakan konsumen terhadap layanan tersebut. Hasil yang didapatkan dari tanggapan responden termasuk ke dalam kategori baik dengan total rata-rata persentase sebesar 74,11\%,. Kepuasan nasabah dipengaruhi secara simultan atau keseluruhan oleh kualitas layanan dengan pengaruh sebesar $39,2 \%$.

Dalam penelitian ini ditetapkan bahwa kepuasan nasabah adalah variabel terikat (dependent variables). Sedangkan untuk variabel bebas (independent variables) adalah dimensi layanan inti e-SERVQUAL (efficiency, fulfillment, reliability, dan privacy). Berikut adalah kerangka hipoesis dalam penelitian ini :

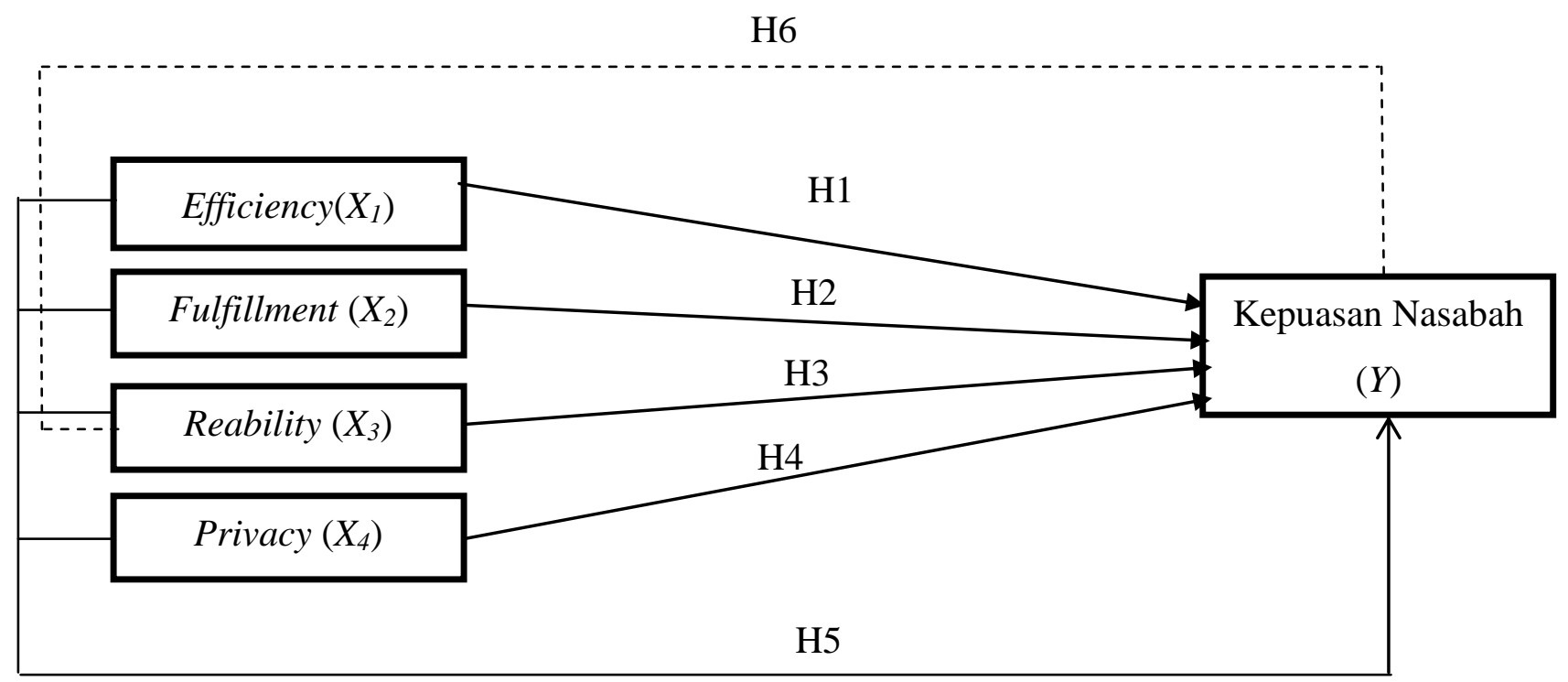

Gambar 2. Kerangka Hipotesis

Hipotesis adalah dugaan sementara yang harus dicari tahu kebenarannya. Pada jenis penelitian kuantitatif menekankan hipotesis pada dua macam, yaitu hipotesis satu variabel dan hipotesis dua variabel atau lebih (Cooper, 2006). Hipotesis yang dapat dirumuskan pada penelitian ini adalah sebagai berikut :

H1 : Terdapat pengaruh antara variabel efficiency $\left(X_{l}\right)$ terhadap kepuasan nasabah (May, 2014). 
$\mathrm{H} 2$ : Terdapat pengaruh antara variabel fullfilment $\left(X_{2}\right)$ terhadap kepuasan nasabah (Pratiwi, 2014).

H3 : Terdapat pengaruh antara variabel reability $\left(X_{3}\right)$ terhadap kepuasan nasabah ( Rahman, 2016).

H4 : Terdapat pengaruh antara variabel privacy $\left(X_{4}\right)$ terhadap kepuasan nasabah (May, 2014).

H5 : Terdapat pengaruh secara simultan (bersama-sama) antara variabel efficiency, fulfillment, reliability, dan privacy terhadap kepuasan nasabah (Pratiwi, 2014).

H6 : Variabel reability $\left(X_{3}\right)$ mempunyai pengaruh yang paling dominan terhadap kepuasan nasabah (Fifip, 2013).

\section{Metode Penelitian}

Untuk mendapatkan bukti sebab akibat, penelitian ini menggunakan rancangan penelitian kausal.Variabel bebas yang mempengaruhi variabel terikat terdiri dari efficiency $\left(X_{1}\right)$, fulfillment $\left(X_{2}\right)$, reliability $\left(X_{3}\right)$, privacy $\left(X_{4}\right)$, sedangkan variabel terikat yang keberadaannya dipengaruhi variabel lainnya adalah kepuasan nasabah $(Y)$ (Cooper, 2006). Metode dalam penelitian ini adalah deskriptif dan verifikatif, yang artinya menggambarkan pengaruh dua variabel atau lebih sesuai dengan kebenaran suatu hipotesis (Sugiyono, 2003).

1) Unsur-unsur yang menjadi dasar dari penelitian perlu dipahami agar dapat sesuai dengan harapan penelitian. Secara rinci operasional variabel penelitian menurut Zeithaml (2002), adalah sebagai berikut:

a. Efficiency, kemampuan pelanggan dalam mencari produk yang diinginkan serta informasi yang dibutuhkan pada saat mengakses website. Indikator : kemudahan dalam mengakses aplikasi, kemudahan registrasi, serta kecepatan dalam mengases situs.

b. Fulfillment, berkaitan dengan fungsi teknis dapat tersedia dan berfungsi baik. Indikator: beragam transaksi yang tersedia, transaksi menjadi lebih praktis dan efektif.

c. Reability, ketersediaan stock produk, akurasi layanan, dan waktu yang dijanjikan.Indikator : bisa diakses kapanpun, akurasi ketepatan waktu dan ketepatan sistem.

d. Privacy, berkaitan dengan jaminan data tidak diberikat kepada pihak lain. Indikator : dapat dipercaya, keamanan informasi pribadi dan data transaksi.

e. Kepuasan nasabah, merupakan perbandingan harapan dan apa yang dirasakan. Indikator : produk sesuai dengn harapan, kesediaan memberikan referensi, dan penggunaan produk secara berkala.

2) Analisis penelitian ini menggunakan pendekatan kuantitatif atau data dalam skala pengukuran statistik (Sugiyono, 2012). Populasi dalam penelitian ini adalah seluruh nasabah Bank Sinarmas Cabang Malang yang aktif menggunakan layanan SimobiPlus.

Tabel 1. Populasi Penelitian

\section{Branch Name Existing to Bank New to Bank Total CIF EasyPin}

\begin{tabular}{lccc}
\hline KC Malang & 177 & 86 & 263 \\
\hline KCP Suprapto & 14 & 12 & 26 \\
\hline KCP Kepanjen & 11 & 8 & 19 \\
\hline KK Singosari & 1 & 7 & 8 \\
\hline KK Turen & 0 & 1 & 1 \\
\hline KK Sengkaling & 0 & 1 & 4 \\
\hline KK Batu & 0 & 4 &
\end{tabular}




\begin{tabular}{cccc}
\hline KK Lawang & 2 & 5 & 7 \\
\hline TOTAL & 205 & 124 & 329 \\
\hline
\end{tabular}

Sumber : Laporan pergerakan CIF EasyPin SimobiPlus , 2017 (Divisi e-channel)

Berdasarkan tabel 1, dapat dilihat bahwa jumlah populasi pengguna layanan SimobiPlus Cabang Malang adalah 329. Pengambilan sampel dalam penelitian ini menggunakan rumus Slovin:

$n=\frac{N}{1+N \cdot e^{2}}$.

Dimana:

$\mathrm{n}=$ jumlah sampel,

N=Jumlah Populasi,

e=Tingkat Kesalahan (10\%),

$1=$ angka konstan.

Berdasarkan rumus di atas, maka diperoleh jumlah sampel minimum 77 responden, sehingga pada penelitian ini jumlah sampel yang diambil adalah 100 responden agar lebih representatif.

Pengumpulan data dalam penelitian ini menggunakan kuesioner standar yang dirancang oleh Zeithamal yaitu e-SERVQUAL. Dalam kuesioner terdapat 15 item untuk menjelaskan 5 variabel yang disebutkan di atas. Responden diminta untuk menjawab pertanyaan pada skala Likert empat poin, dengan skor $1=$ sangat tidak setuju, $2=$ tidak setuju, 3 = setuju, dan 4 = sangat setuju. Alasan menggunakan empat poin karena kategori ragu-ragu atau netral tidak perlu dimasukkan ke dalam kuesioner apabila responden tidak memberikan alasan (Umar, 2010). Dalam penyebarannya, kuesioner memanfaatkan layanan google forms dan dikirim ke e-mail nasabah. Cara ini bisa dibilang efektif karena menghemat waktu dan biaya.

Teknik analisis data dalam penelitian ini adalah menggunakan analisis regresi berganda dengan persamaan sebagai berikut: $Y=a+b 1 \times 1+b 2 \times 2+b 3 \times 3+b 4 \times 4+b 5 \times 5+e$

Dimana: $\mathrm{Y}=$ kepuasan nasabah, $\mathrm{a}=$ konstanta, $\mathrm{b}=$ koefesien korelasi, $\mathrm{x}=$ variabel penelitian, $\mathrm{e}=$ tingkat kesalahan. Dalam pengujian hipotesis menggunakan Uji Validitas, Uji Reabilitas, Analisis Koefisien Determinasi (R2), Uji T (Parsial), dan Uji F(Simultan),

\section{Hasil Pembahasan}

Dari hasil pengumpulan data, didapatkan karakteristik responden berdasarkan jenis kelamin sebesar $61 \%$ didominasi oleh perempuan, sisanya $39 \%$ adalah laki-laki. Berdasarkan usia didominasi oleh usia antara 21-30 tahun sebesar 57\%, 31-40 tahun sebesar 25\%, 41-50 tahun sebesar $11 \%$, kurang dari 20 tahun sebesar 4\%, sisanya $3 \%$ adalah usia diatas 50 tahun. Berdasarkan pekerjaan sebesar $43 \%$ merupakan pegawai swasta, $28 \%$ merupakan wiraswasta, $11 \%$ merupakan pegawai negeri sipil, $9 \%$ adalah mahasiswa, dan sisanya $9 \%$ adalah ibu rumah tangga.

Dari hasil analisis statistik deskriptif, responden sebanyak $63.3 \%$ menyatakan sangat setuju dan $36.7 \%$ menyatakan setuju pada variabel efficiency.Pada variabel fulfillment, $66 \%$ responden menyatakan sangat setuju dan 34\% menyatakan setuju. Pada variabel reability, $66,7 \%$ responden menyatakan sangat setuju dan 33,3\% menyatakan setuju. Pada variabel privacy, $62 \%$ responden menyatakan sangat setuju dan $38 \%$ menyatakan setuju. Pada variabel kepuasan nasabah $61 \%$ responden menyatakan sangat setuju dan $39 \%$ menyatakan setuju. 


\section{A. Uji Validitas dan Reabilitas}

Uji validitas harus ditetapkan sebelum menguji teori (Davis, 1989). Valid tidaknya kuesioner tergantung dari kemampuan pernyataan mengungkap suatu yang akan diukur. (Ghozali, 2006). Hasil output dengan menggunakan SPSS 22 adalah sebagai berikut:

Tabel 2. Hasil Uji Validitas

\begin{tabular}{cccc} 
& $\mathbf{r}$ & $\mathbf{r}$ & \\
\cline { 2 - 3 } Item & hitung & Ket. \\
\cline { 2 - 3 } & 0.476 & tabel & \\
\hline$X_{1.1}$ & 0.363 & 0.195 & Valid \\
\hline$X_{1.2}$ & 0.522 & 0.195 & Valid \\
\hline$X_{1.3}$ & 0.486 & 0.195 & Valid \\
\hline$X_{2.1}$ & 0.449 & 0.195 & Valid \\
\hline$X_{2.2}$ & 0.499 & 0.195 & Valid \\
\hline$X_{2.3}$ & 0.474 & 0.195 & Valid \\
\hline$X_{3.1}$ & 0.454 & 0.195 & Valid \\
\hline$X_{3.2}$ & 0.442 & 0.195 & Valid \\
\hline$X_{3.3}$ & 0.409 & 0.195 & Valid \\
\hline$X_{4.1}$ & 0.404 & 0.195 & Valid \\
\hline$X_{4.2}$ & 0.421 & 0.195 & Valid \\
\hline$X_{4.3}$ & 0.429 & 0.195 & Valid \\
\hline$Y_{1.1}$ & 0.475 & 0.195 & Valid \\
\hline$Y_{1.2}$ & 0.518 & 0.195 & Valid \\
\hline$Y_{1.3}$ & & 0.195 &
\end{tabular}

Sumber: Data Diolah, 2017

Berdasarkan tabel 2, menunjukkan bahwa nilai korelasi product moment (r-hitung) untuk masing-masing item pertanyaan lebih besar dari nilai r-tabel sebesar 0.195 (taraf signifikan $5 \%$ dan $\mathrm{n}=100$ ). Sehingga dapat disimpulkan bahwa keseluruhan item pernyataan kuesioner dinyatakan valid.

Reliabilitas merupakan suatu pengukuran yang menghasilkan ketepatan (Gronlund, 1990). Cronbach alpha merupakan hasil uji reabilitas dimana item pernyataan dikatakan reliable apabila memiliki nilai $\geq 0,6$ (Nunnally, 1978). Hasil output dengan menggunakan SPSS 22 adalah sebagai berikut:

Tabel 3. Hasil Uji Reabilitas

Cronbach's Alpha Cronbach's Alpha Based on Standardized Items

NOfItems

0.714 0.788 16

Sumber : Data Diolah, 2017

Berdasarkan tabel 3, menunjukkan bahwa nilai cronbach alpha 0,714>0.6 yang artinya dapat diterima. Jika dilihat dari Cronbach's Alpha Based on Standardized Items nilai tersebut merupakan nilai reliabilitas tes secara keseluruhan, semakin besar nilainya berarti 
semakin reliabel. Jika dilihat menggunakan $\mathrm{r}$ tabel pada $\mathrm{DF}=\mathrm{N}-2$ dan Probabilitas 0.05 maka jumlah sampel (100)-2=98. $\mathrm{r}$ tabel pada DF 98 Probabilitas 0.05 adalah 0.1966, dengan demikian nilai Cronbach's Alpha Based on Standardized Items $0.788>\mathrm{R}$ tabel 0.1966 yang berarti tes secara keseluruhan reliabel. Sehingga dapat disimpulkan bahwa keseluruhan item dalam kuesioner dinyatakan reliabel.

\section{B. Analisis Regresi Linier Berganda}

Analisis regresi linier berganda adalah hubungan secara liniear antara variabel bebas dengan variabel terikat untuk melihat pengaruh positif atau negatif variabel kepuasan nasabah apabila variabel ketika variabel efficiency, fullfilment, reability, dan privacy mengalami penurunan atau kenaikan(Sugiyono, 2011). Hasil output dengan menggunakan SPSS 22 adalah sebagai berikut:

Tabel 4. Coefficients ${ }^{a}$

\begin{tabular}{ccccc}
\hline \multirow{2}{*}{ Model } & \multicolumn{2}{c}{ Unstandardized Coefficients } & & \multirow{2}{*}{ Sig. } \\
\cline { 2 - 3 } & $\boldsymbol{B}$ & Std. Error & & \\
\hline (Constant) & 0.492 & 0.92 & 0.54 & 0.593 \\
\hline$X_{1}$ & 0.218 & 0.08 & 2.75 & 0.007 \\
\hline$X_{2}$ & 0.183 & 0.08 & 2.22 & 0.029 \\
\hline$X_{3}$ & 0.296 & 0.08 & 3.56 & 0.001 \\
\hline$X_{4}$ & 0.248 & 0.09 & 2.75 & 0.007 \\
\hline
\end{tabular}

Sumber : Data diolah, 2017

Berdasarkan tabel 4, menunjukkan constanta positif yang menunjukkan pengaruh positif variabel bebas (efficiency, fulfillment, reability, privacy), dapat disusun persamaan regresi berganda sebagai berikut:

$\mathrm{Y}=\mathrm{a}+0.218 \mathrm{X} 1+0.183 \mathrm{X} 2+0.296 \mathrm{X} 3+0.248 \mathrm{X} 4+\mathrm{e}$, dengan pengertian sebagai berikut:

$\mathrm{a}=0.492$, artinya apabila $\mathrm{X} 1=\mathrm{X} 2=\mathrm{X} 3=\mathrm{X} 4=0$, maka nilai $\mathrm{Y} 0.492$

$\mathrm{b} 1=0.218$, artinya apabila $\mathrm{X} 2, \mathrm{X} 3, \mathrm{X} 4$ dan X5 adalah 0, kenaikan X1 sebesar 1 satuan akan menyebabkan kenaikan Y sebesar 0.218 kali menjadi sebesar 0.492

b2 $=0.183$, artinya apabila X1,X3,X4 dan X5 adalah 0, kenaikan X2 sebesar 1 satuan akan menyebabkan kenaikan Y sebesar 0.183 kali menjadi sebesar 0,492

b3 $=0.296$, artinya apabila X1,X2,X4 dan X5 adalah 0, kenaikan X3 sebesar 1 satuan akan menyebabkan kenaikan Y sebesar 0.296 kali menjadi sebesar 0.492

b4 $=0.248$, artinya apabila X1,X2,X3 dan X5 adalah 0, kenaikan X4 sebesar 1 satuan akan menyebabkan kenaikan Y sebesar 0.248 kali menjadi sebesar 0.492

\section{Analisis Koefesien Determinasi $\left(\mathbf{R}^{2}\right)$}

Dalam pengujian hipotesis koefesien determinasi $\left(\mathrm{R}^{2}\right)$, diperoleh informasi tentang besarnya pengaruh dari keseluruhan variabel bebas dan variabel terikat. Hasil output dengan menggunakan SPSS 22 adalah sebagai berikut: 
Tabel 5. Analisis Koefesien Determinasi $\left(\mathrm{R}^{2}\right)$

\begin{tabular}{cccc}
\hline $\boldsymbol{R}$ & $\boldsymbol{R}$ Square & Adjusted $\boldsymbol{R}$ Square & Std.Error \\
\hline $.758^{\mathrm{a}}$ & 0.575 & 0.557 & 0.544 \\
\hline
\end{tabular}

Sumber : Data diolah, 2017

Berdasarkan tabel 5, dapat dilihat besarnya pengaruh variabel bebas terhadap variabel terikat. Dalam penelitian ini menggunakan Adjusted R Square-nya sebesar 0.557 atau 55.7\% karena regresi dalam penelitian ini menggunakan lebih dari 2 variabel bebas (Santoso, 2001). Jadi dapat disimpulkan bahwa kepuasan nasabah pengguna layanan SimobiPlus dipengaruhi oleh variabel efficiency, fulfillment, reliability, dan privacy sebesar 55.7\%. Sisanya sebesar $44.3 \%$ dipengaruhi oleh faktor lain yang tidak menjadi objek penelitian ini.

\section{Uji T (Parsial)}

Menurut Ghozali (2006), dasar dari pengujian uji t adalah untuk melihat seberapa jauh pengaruh variabel bebas secara individu terhadap variabel terikat. Diketahui $\mathrm{t}$ tabel dengan tingkat signifikansi 0.05/2=0.025 (uji dua sisi) sebesar 1.98. Dari tabel 4. Coefficients $^{a}$ di atas, dilihat bahwa t hitung untuk variabel efficiency sebesar $2.75>1.98$, fulfillment sebesar $2.22>$ 1.98 , reability sebesar $3.56>1.9$, dan privacy sebesar $2.75>1.98$. Selain itu dapat dilihat nilai nilai sig. pada masing-masing variabel, variabel efficiency sebesar $0.007<0.05$, fulfillment sebesar $0.029<0.05$, reability sebesar $0.001<0.05$, dan privacy sebesar $0.007<$ 0.05. Maka dapat disimpulkan bahwa masing-masing variabel bebas (efficiency, fullfillment, reabiltity, dan privacy) berpengaruh secara positif dan signifikan terhadap kepuasan nasabah.

\section{E. Uji F (Simultan)}

Menurut Ghozali (2012), dasar pengujian uji f adalah untuk melihat apakah semua variabel bebas yang dimasukkan dalam model regresi bersama-sama berpengaruh terhadap variabel terikat. Hasil output dengan menggunakan SPSS 22 adalah sebagai berikut:

Tabel 6. ANOVA ${ }^{a}$ (Analysis Of Variance)

\begin{tabular}{cccccc}
\hline Model & Sum of Square & df & Mean Square & F & Sig. \\
\hline Regression & 38.001 & 4 & 9.5 & 32 & $.000^{\mathrm{b}}$ \\
\hline Residual & 28.109 & 95 & 0.296 & & \\
\hline Total & 66.11 & 99 & & \\
\hline
\end{tabular}

Sumber : Data Diolah, 2017

Berdasarkan tabel 6, dapat dilihat bahwa f hitung sebesar 32.108 lebih besar dari f tabel 2.47. Selain itu dapat dilihat bahwa nilai Sig. lebih kecil daripada 0,05. Maka dapat disimpulkan bahwa keseluruhan variabel (efficiency, fullfillment, reabiltity, dan privacy) secara bersamasama berpengaruh secara simultan terhadap kepuasan nasabah.

\section{Kesimpulan}

Hasil penelitian menunjukkan bahwa keempat variabel e-SERVQUAL berpengaruh 
secara signifikan terhadap kepuasan nasabah. Dimensi terkuat dalam menjelaskan kualitas layanan elektronik secara berturut-turut adalah reability, efficiency, privacy, dan fulfillment.Faktor yang mempengaruhi variabel reability mempunyai pengaruh terkuat terhadap kepuasan nasabah dikarenakan Sinarmas Mobile Banking atau SimobiPlus mampu memberikan layanan sesuai yang dijanjikan secara akurat dan dapat diandalkan. Penelitian ini menunjukkan pengaruh yang positif antara kualitas layanan elektronik (e-SERVQUAL) terhadap kepuasan nasabah pengguna Sinarmas mobile banking. Hal ini terbukti dari hasil penelitian yang menunjukkan bahwa sebesar 55.7\% variabel kepuasan nasabah dijelaskan oleh keempat variabel e-SERVQUAL, sedangkan sisanya $44.3 \%$ dipengaruhi oleh faktor lain diluar variabel layanan inti dimensi e-SERVQUAL.

Saran dalam penelitian ini agar industri perbankan Indonesia terus berinovasi terhadap layanan perbankan elektronik sesuai dengan harapan nasabah. Karena selain memberikan kemudahan untuk nasabah, layanan elektronik memberikan keuntungan bagi pihak bank untuk menekan biaya operasional.

\section{Daftar Pustaka}

Anugrah, R. (2015). Pengaruh Kualitas Layanan Internet Banking Terhadap Kepuasan dan Loyalitas Nasabah Pada PT.Bank Negara Indonesia (Persero) Tbk. Di Kota Makassar. Manajemen Ekonomi dan Bisnis.

Cooper, D. (2006). Business Research Methods (9th ed.). New York: McGraw-Hill/Irwin.

Davis, F. B. (1989). User Acceptance of Computer Technology: A Comparison of Two Theoretical Models. Management Science, 35.

Ensor, B. M. (2012). The state of Mobile Banking.

Gan, C. C. (2006). A logit Analysis of Electronic Banking in New Zealand,. International Journal of Bank Marketing, Vol. 24, No. 6, hal. 360-383.

Gazor, H. N. (2012). Analyzing Effects of Service Counter Quality on Customer Satisfaction in Banking Industry. Management Science Letters.

Ghozali, I. (2006). Aplikasi Analisis Mulitivariate dengan Program SPSS. Semarang: Universitas Diponegoro.

Ghozali, I. (2012). Aplikasi Analisis Mulitivariate dengan Program IBM SPSS 20. Semarang: Universitas Diponegoro.

Gronlund, N. E. (1990). Mesurement and Evaluation in Teaching. Macmillan Publishing Company.

Https://www.emarketer.com

Kasmir. (2008). Bank dan Lembaga Keuangan Lainnya. Jakarta: Rajagrafindo Persada.

Kinnear, T. T. (1988). Marketing Research: An Applied Approach. Jakarta: Erlangga (Terjemahan).

Kusumaningrum, P. (2014). Pengaruh Kualitas Jasa Mobile Banking Terhadap Kepuasan Nasabah PT. Bank Mandiri (Persero) Tbk Cabang Makassar. Manajemen Ekonomi dan Bisnis.

Malhotra, N. (2004). Marketing Research : an Applied Orientation. Pearson Education.

Mallat, T. D. (2002). Mobile Payment Service Development. Managerial Implication Of Customer Value Perception.

May Fanny Eka Putri, D. T. (2014). Pengaruh kualitas layanan elektonik (e-SERVQUAL) Terhadap Kepuasan Nasabah Pengguna Mobile Banking. Manajemen Bisnis 
Telekomunikasi dan Informatika.

Nunnally, J. C. (1978). Assessment of Reliability. Psychometric Theory.

O, Fifif. C. (2013). Pengaruh Kualitas Layanan Internet Banking KlikBCA Terhadap Kepuasan Pelanggan. Ekonomi Manajemen.

O'Connor, S. T. (2000). Perceptual Gaps in Understanding Patient Expectations for Health Care Service Quality. Health Care Management Review, 23.

Parasuraman, A. (1985). A Conceptual Model of Service Quality and Its Implications for Future Research. The Journal of Marketing, Vol. 49 No. 4, pp. 41-50.

Parasuraman, A. (1988). SERVQUAL: A Multiple Item Scale for Measuring, Consumer Perceptions of Service Quality. Journal of Retailing, Vol. 64 No. 1, pp. 12-40.

Santoso. (2001). Mengolah Data Statistik Secara Profesiona. Yogyakarta: BPFE Yogyakarta. Singarimbun, S. (1989). Metode Penelitian Survei. Jakarta: LP3ES.

Sugiyono. (2003). Metode Penelitian Bisnis. Bandung: Alfabeta.

Sugiyono. (2004). Metode Penelitian Bisnis. Bandung:Alfabeta.

Sugiyono. (2010). Stasistik untuk Pendidikan. Bandung: Alfabeta.

Sugiyono. (2011). Statistik untuk penelitian. Bandung: Alfabeta.

Sugiyono. (2012). Metode Penelitian Bisnis. Bandung: Alfabeta.

Suoranta, M. a. (2004). Mobile banking and customer behavior:New insights into the diffusion pattern. Journal of Financial Services Marketing, Vol. 8 No. 4, pp. 354-366.

Umar, H. (2010). Riset Pemasaran \& Perilaku Konsumen. Jakarta: Gramedia.

Yuan, X. H. (2010). Resent and Future of Internet Banking . Journal of Internet Banking and Commerce, Vol. 15, No. 1.

Zeithaml, V. B. (1996). The Behavioral Consequences of Service Quality. Journal of Marketing, 1-5

Zeithaml, V. P. (2000). E-Service Quality : Definition, Dimensions and Conceptual Model . Cambridge, MA: Working Paper, Marketing Science Institute.

Zeithaml, V. P. (2001). A Conceptual Framework for Understanding-Service Quality: Implication for Future Research and Managerial Practice. MSI Working Paper Series.

Zeithaml, V. P. (2002). Service Quality Delivery Through Web sites: Critical Review of Extant knowledge. Journal of the Academy of Marketing Science, 362. 